\title{
Thyroid Hormone and Dementia
}

\author{
Hidekatsu Yanai
}

Thyroid hormones are important in the development of the brain in early life [1]. A recent comprehensive review of the literature based on the current knowledge of the effects of thyroid hormones on brain and their role in Alzheimer's disease suggested that thyroid hormones produce significant neurological effects, act as neuroprotective agents and might be considered as future diagnostic and therapeutic tools for Alzheimer's disease [2]. Women with atrial fibrillation with levothyroxine treatment and hypothyroidism have been reported to have a lower risk of incident dementia than women with atrial fibrillation without levothyroxine treatment and no hypothyroidism [3], supporting a result of comprehensive review [2]. Thyroid hormones may play an important role in the brain function in both early and late life.

In this issue (J Endocrinol Metab, 2019), George et al reported that subclinical hypothyroidism was associated with reduced risk of dementia, whereas overt hyperthyroidism, particularly very elevated free $\mathrm{T} 4$, was associated with increased risk of dementia [4]. Which of hyperthyroidism or hypothyroidism is better for prevention of dementia? Rieben et al conducted a meta-analysis of prospective cohort studies $(\mathrm{n}=11)$ to understand the association between subclinical thyroid dysfunction and the risk of cognitive decline [5]. In random-effects models, the pooled adjusted risk ratio for dementia in subclinical hyperthyroidism was 1.67 (95\% confidence interval (CI): 1.04 - 2.69) and 1.14 (95\% CI: 0.84 - 1.55) in subclinical hypothyroidism vs. euthyroidism, which agrees with the result by George et al. Pasqualetti et al performed the systematic review and meta-analysis on subclinical hypothyroidism and cognitive impairment [6]. A significant risk of cognitive alteration was observed only in subclinical hypothyroidism individuals younger than age 75 years: composite endpoint odds ratio (OR) 1.56 (95\% CI: $1.07-2.27, \mathrm{P}=0.02)$, risk of dementia OR 1.81 (95\% CI: $1.43-2.28, \mathrm{P}<0.01)$. Mean serum thyroidstimulating hormone (TSH) levels and the OR of composite endpoint were positively correlated. No significant effect of subclinical hypothyroidism was found when considering all the studies as a whole.

It remains unknown which of hyperthyroidism or hypothyroidism is better for prevention of dementia. It is necessary to continue the studies taking into consideration of age, treat-

Manuscript submitted July 24, 2019, accepted August 7, 2019

Department of Diabetes, Endocrinology and Metabolism, National Center for Global Health and Medicine Kohnodai Hospital, 1-7-1 Kohnodai, Ichikawa, Chiba 272-8516, Japan. Email: dyanai@hospk.ncgm.go.jp ment content, treatment goals, appropriate markers for thyroid dysfunction (TSH, free T4, etc.) of the study subject with thyroid dysfunction.

\section{Acknowledgments}

Not applicable.

\section{Financial Disclosure}

Author has no financial disclosures to report.

\section{Conflict of Interest}

The author declares that he has no conflict of interest concerning this article.

\section{References}

1. Rovet JF. The role of thyroid hormones for brain development and cognitive function. Endocr Dev. 2014;26:26-43.

2. Accorroni A, Chiellini G, Origlia N. Effects of thyroid hormones and their metabolites on learning and memory in normal and pathological conditions. Curr Drug Metab. 2017;18(3):225-236.

3. Wandell P, Carlsson AC, Sundquist J, Sundquist K. Effect of levothyroxine treatment on incident dementia in adults with atrial fibrillation and hypothyroidism. Clin Drug Investig. 2019;39(2):187-195.

4. George KM, Lutsey PL, Selvin E, Palta P, Windham BG, Folsom AR. Association between thyroid dysfunction and incident dementia in the atherosclerosis risk in communities neurocognitive study. J Endocrinol Metab. 2019;9(4):82-89.

5. Rieben C, Segna D, da Costa BR, Collet TH, Chaker L, Aubert CE, Baumgartner C, et al. Subclinical thyroid dysfunction and the risk of cognitive decline: a meta-analysis of prospective cohort studies. J Clin Endocrinol Metab. 2016;101(12):4945-4954.

6. Pasqualetti G, Pagano G, Rengo G, Ferrara N, Monzani F. Subclinical hypothyroidism and cognitive impairment: systematic review and meta-analysis. J Clin Endocrinol Metab. 2015;100(11):4240-4248.

doi: https://doi.org/10.14740/jem592 